\title{
Isolation and Identification of Streptococcus pneumonia Causing Respiratory and Thoracic Diseases in Najaf Province
}

\author{
Hazim Aziz Naji AL-Hadrawi ${ }^{1 *}$ (D), Raad A. AL-Harmoosh ${ }^{1,2}$ (D) and Hawraa Natiq \\ Kabroot AL-Fatlawy² (D)
}

${ }^{1}$ College of Science, University of Kufa, Najaf, Iraq. ${ }^{2}$ Department of Medical Laboratory Techniques, Al-Toosi University College, Najaf, Iraq.

\begin{abstract}
This Study aims to isolation and identification of Streptococcus pneumonia from patients' sputum in Najaf governorate. Among 120 samples were collected from patients that are expected to have pneumonia acquired from community in the Center for Respiratory and Thoracic diseases in the Najaf governorate in Al-Sadder medical city. All samples taken from patients after diagnosis by physicians based on the clinical symptoms as well as photographic radiography. Samples were divided into five groups according to the age of patient and the samples collected between April 2018 and the end of March 2019 from both males and females. The results showed the pneumonia rates varied among the months of period study. The highest rate was in November 2018 . But the lowest percentage in the march 2019. The highest number was 24 patients in the age of more than 50 years. But the lowest number was 12 in the age of 20-30 years. The results of the current study showed that number of males infected was superior by 51 cases in contrast 29 in females. The current study results also showed different antibiotics sensitivity patterns. All isolates were resistance towards gentamicin, ampicillin, amoxicillin and tetracycline. And one isolate which was sensitive to polymyxin.
\end{abstract}

Keywords: Streptococcus pneumonia, sputum, antibiotics sensitivity, amoxicillin and tetracycline.

*Correspondence: hazim.alhadrawi@uokufa.edu.iq

(Received: 27 October 2019; accepted: 23 November 2019)

Citation: Hazim Aziz Naji AL-Hadrawi, Raad A. AL-Harmoosh and Hawraa Natiq Kabroot AL-Fatlawy, Isolation and Identification of Streptococcus pneumonia Causing Respiratory and Thoracic Diseases in Najaf Province, J Pure Appl Microbiol., 2019; 13(4):2235 2240. https://doi.org/10.22207/JPAM.13.4.37

(C) The Author(s) 2019. Open Access. This article is distributed under the terms of the Creative Commons Attribution 4.0 International License which permits unrestricted use, sharing, distribution, and reproduction in any medium, provided you give appropriate credit to the original author(s) and the source, provide a link to the Creative Commons license, and indicate if changes were made. 


\section{INTRODUCTION}

Pneumonia was described more than two thousandth year ago; by Hippocrates who studied pneumonia throughout his career called pneumonia the captain of the men of death because of, the great toll it exacted on human. Pneumococcal disease is one of diseases infection caused by Streptococcus pneumonia bacteria so called pneumococcus. These bacteria can cause many types of diseases, including: sinus infections, pneumonia infection of the lungs as well as ear infections, bacteremia and meningitis infection of the covering around the brain and spinal cord. Pneumonia are spread through cough, close contact with an infected peoples and sneezing ${ }^{1,2}$.

Streptococcus pneumonia have many virulence factors such as polysaccharides; surface proteins and cytoplasmic proteins. These factors have the characteristics of the pneumonia ${ }^{3}$. The infection causes inflammation process which develops after autolysis causes the lysis of bacteria. Thus inflammation also involves components of the cell wall; the toxin pneumolysin.

Symptoms of pneumococcus infection depending on the part of the body that is infected. They can include chest pain, fever, cough, stiff neck, confusion, disorientation, ear pain, sensitivity to light, sleeplessness, joint pain, chills, and irritability. In severe cases, pneumococcal disease can cause hearing loss, brain damage, and death ${ }^{1,4}$. Most children are colonized with Streptococcus and become carriers of one or more strains of $S$. pneumonia during the first year of life asymptomatic ${ }^{5}$. Conjugate pneumococcal vaccine reduces the carriage rate of Streptococcus pneumonia strains ${ }^{6}$.

More than $70 \%$ of persons hospitalized with pneumonia died that before the availability of antibiotics $^{3,7}$. Antimicrobials influence against pneumococcus, and the outcome of patients with pneumonia infections improved substantially. The decrease efficacy of penicillin led to the widespread of pneumococcal infections, and so that clinicians, researchers, and public health workers lost their favored drug of choice for prevention of this pathogen.

Aspiration pneumococcus may show bilateral opacities primarily; in the bases of the lungs and on the right side ${ }^{8}$. When hospitalized for pneumonia, both lower respiratory tract samples and blood cultures, as well as testes the urine samples for antigen to Legionella spp. and pneumonia ${ }^{9,10}$.

Pneumonia may be develop in healthy people and may become more variable depending on the properties of the person ${ }^{11}$. So pneumonia was the third disease classified by the U.S. leading to death before the advent of antibiotics in last century about mid-thirties ${ }^{11,12}$. In S. pneumonia, multidrug resistance was first observed in 1977 and has been widely spread since ${ }^{13}$. Rapid development of antibiotic resistance in S. pneumonia has been a global concern and a growing numbers of reports have shown that bacterial pneumonia may not respond to available antibiotics in many settings ${ }^{14}$. The current study is carried out to achieve the following objectives:

1- Isolation and identification of Streptococcus pneumonia from patients' sputum samples.

2- Detection the antibiotics sensitivity patterns towards gentamicin, ampicillin, amoxicillin and tetracycline antibiotics.

\section{MATERIALS AND METHODS}

The total (120) samples from patients with suspected pneumonia acquired from the community and hospital- acquired pneumonia for the period from April 2018 to the end of March 2019 in the Center for Respiratory and Thoracic diseases in Al-Sadder medical city in the Najaf Province.

\section{Examination of sputum Includes two steps}

A- the first is staining with Ziehl- Neelsoon stain according to Newcomer Supply, Inc.

$B$ - the second steps is staining with gram stain as well as the sputum culture by cultivate the sputum sample an equal amount of saline solution was added to the sputum and homogenized by mixing it by a shaker for half minute then cultured according to ${ }^{15}$.

\section{Antimicrobial susceptibility test}

The antimicrobial sensitivity test has been applied by disk diffusion manner by Kirby- Bauer as mention in ${ }^{16}$. After incubation for one hour at $37^{\circ} \mathrm{C}$, the density of the suspension was adjusted according to (0.5) McFarland standards which are equal to bacterium turbidity of $\left(1.5 \times 10^{8}\right)$ cells $/ \mathrm{ml}$ by adding sterile normal saline. A sterile cotton 
swab was used to obtain inoculum to be streaked on Muller-Hinton agar. The antimicrobial discs were placed on the surface of the medium at evenly spaced intervals. Incubate the plate at $37^{\circ} \mathrm{C}$. Antibiotic inhibition zone was measured by using ruler. Zone diameter was compared to standard results being recommended by clinical laboratory standards institute documentations ${ }^{17}$.

\section{RESULTS AND DISCUSSION}

The current study showed contradictory results among collected samples. During the study period, pneumonia rates varied among the months of study period. The highest rate was in November 2018, but the lowest percentage in the March 2019. While the remaining months differed in their isolation rate, as shown in [Fig. 1].The results showed that the most cases of pneumonia infection were in November 2018, may be due to viral diseases seasonal incidence that are more pronounced in adults than in children. The current results were agreement with the results of ${ }^{11}$. There is no data about the distribution of isolations prevalence and year months in the Iraqi studies till now.

In other hand, the results depending on the age. The age results were divided into five groups, The first group was between 10-20 years old, 14 case only, and the second group was between 20-30 years old, 13 case, but the third group was between $30-40$ years old 17 case, while, the other group was between 40-50 years which found only 12 case; and the last group was above 50 years it was 24 case as show in [Fig. 2].

The results showed the number of people with pneumonia gradually increases with age increase. The highest number was 24 patients in the age of more than 50 years, but the lowest number was 12 in the age range of 20-30 years. The advanced age of the person is accompanied by a decrease in the

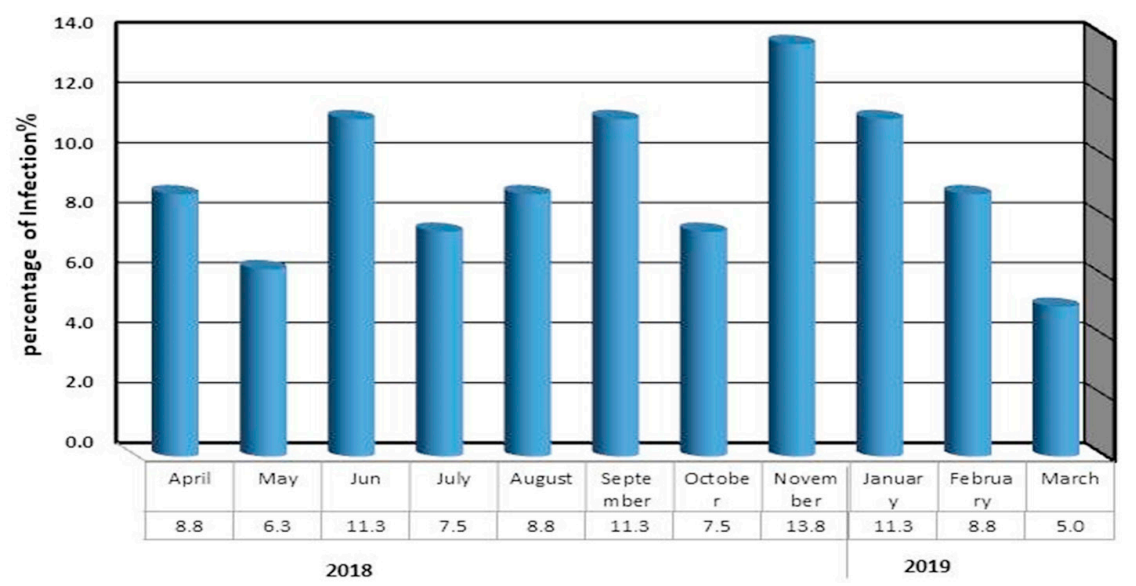

Fig. 1. Distribution of Streptococcus pneumonia isolates based on the seasonal infection in months

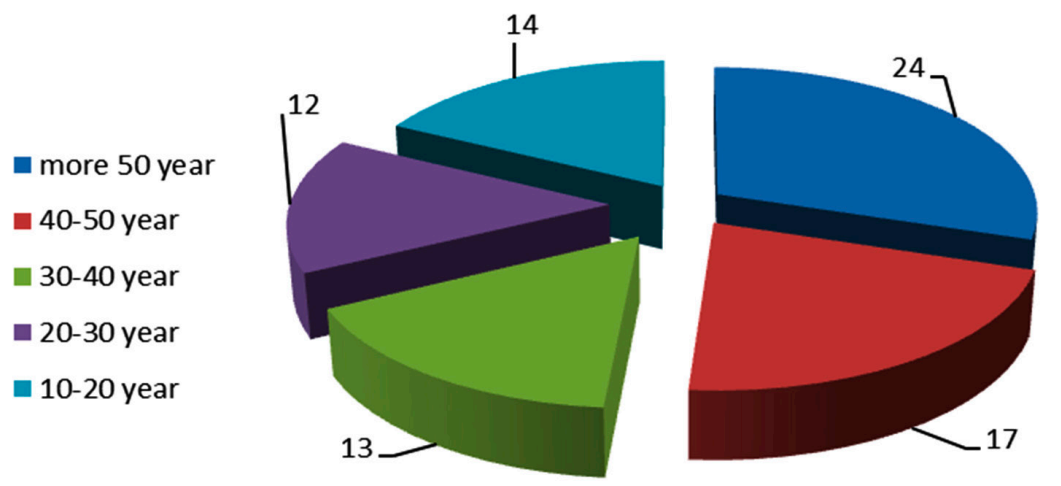

Fig. 2. Distribution of Streptococcus pneumonia infections based on patient age 


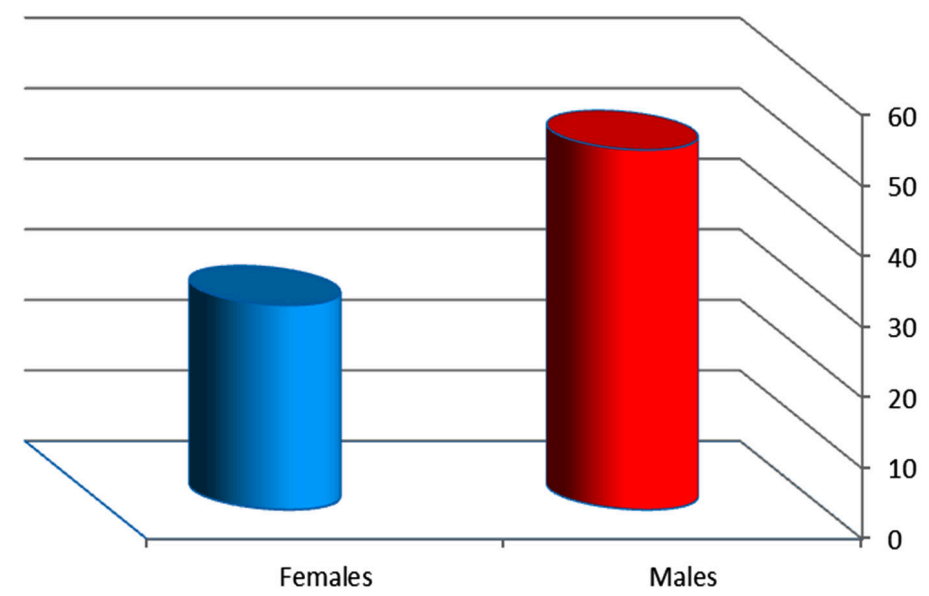

Fig. 3. Distribution of pneumonia infections based on gender

defenses of the physical barriers and the decline in protection against invading pathogens as well as change in the immune system associated with age, that very important factors for the establishment of pneumonia ${ }^{18}$. Other studies indicated about $20 \%$ of the cases were in the age group 70 years and above, as well as the study which showed that the rate of infection increase from 50 years and more ${ }^{19}$. Human immune defenses is not only triggered by the exposure to pneumonia cell, but also shows response to surface proteins, and capsular polysaccharide, Because of The human immune system is capable of clearing pneumococcal colonization but the time required for clearance depends on host age and bacterial serotypes ${ }^{20,21}$. Immune responses to colonization are complex, comprising both innate and adaptive immunities with the latter playing a greater role after the first year of life.

The results of the current study showed that 51 isolates from males patients and 29 isolates for females as show in [Fig. 3]. Yang and his colleague ${ }^{22}$ that indicated the study focused on the cause of female resistance to pneumonia compared to males, the female sex hormone called estrogen have been found to enhanced the role of macrophage to kill bacteria. So this results was compatible with many studies such as Khan and his colleague ${ }^{12}$ and Amissah and Pappoe ${ }^{23}$ which mentions were $138(53.28 \%$ ) and $65(62.2 \%)$ respectively. Also the reason may be that males were smokers at a higher rate compared to females which increases their risk of pneumonia.
The current study results agreement with a local study done by Motaweq and Naher ${ }^{24}$ that showed patients in the age groups 51-60 years had a high percentage of S. pneumonia isolates (19.7\%) compared with other age groups with a significant variation $(P<0.05)$ between them. Males $(54 \%)$ showed a higher percentage of $S$. pneumoniae isolates than females $(45.9 \%)$ with no significant variation $(P>0.05)$. Smokers have been shown to have increased risk to LRTI than non-smokers $(P>0.05)$, and there was no significant variation between Urban and Rural (56.8:43.2\%) Patients.

All isolates were resistance towards gentamicin and polymyxin, except one isolate which was sensitive to the polymyxin. Moreover the results showed all isolates were resistance for ampicillin, amoxicillin and tetracycline. The results also showed all isolates were sensitive for cefotaxime and ceftazidime. The resistance to these antibiotics has been come closed with previous study in Iraq done by Mahdi he worked on the common bacterial causes isolated from patients with community acquired pneumonia ${ }^{25}$. While studies in other countries such as Asadi and his colleague ${ }^{26}$ in Iran indicated the amoxicillin resistance against of S. pneumonia was $32.3 \%$ only, that may be occurred due to changes in the genetic materials of the bacteria by some mechanisms such as spontaneous mutations in chromosomal gene or plasmids the resistance that occurred by transposable elements from resistant strain to sensitive strain ${ }^{27}$. 


\section{CONCLUSION}

We conclude that there was high frequency of Streptococcus pneumonia from patient's sputum in Najaf Province, there is a significant variation of pneumonia isolation rates among months of period study; and there is high levels of resistance towards the antibiotics used in this study.

\section{ACKNOWLEDGEMENTS}

The authors are thankful to department of Ecology, College of Science, University of Kufa.

\section{CONFLICTS OF INTEREST}

The authors declare that there is no conflict of interest.

\section{FUNDING}

None.

\section{AUTHORS' CONTRIBUTION}

All authors have made substantial, direct and intellectual contribution to the work and approved it for publication.

\section{DATA AVAILABILITY}

All datasets generated or analyzed during this study are included in the manuscript.

\section{ETHICS STATEMENT}

This article does not contain any studies with human participants or animals performed by any of the authors.

\section{REFERENCES}

1. Wen, Z., Sertil, O., Cheng, Y., Zhang, S., Liu., X., Wang, W.C., and Zhang, J.R. The sequence elements upstream of the core promoter are necessary for the full transcription of the capsule gene operon in Streptococcus pneumonia strain D39. Infection and Immunity, 2015; 83: 1957-72. https://doi. org/10.1128/IAI.02944-14

2. Al-Dahmoshi, H.O.M. Rapid Investigation of Uncultivable Respiratory Tract Bacteria Among Tuberculosis Patients in Hilla City, Iraq. Research Journal of Pharmaceutical Biological and Chemical Sciences, 2016; 7(6): 2723-2729.

3. Skovsted, I.C. Textbook in Diagnosis, Serotyping, Virulence Factors and Enzyme-linked Immunosorbent Assay (ELISA) for Measuring Pneumococcal Antibodies. SSI Diagnostica A/S, $4^{\text {th }}$ Edition, 2017.

4. Alhabeeb, Z., Abed Alftah, Alh-hasnawi, Abeer, T., Naji and Alhasnawy, Huda, H. Role of Toll Like Receptor -9
Gene Polymorphism among patients with Exacerbation Chronic Obstructive Pulmonary Disease in Holy Karbala/ Iraq. Indian Journal of Public Health Research \& Development, 2019; 10(6): 1001-1006. https://doi. org/10.5958/0976-5506.2019.01414.1

5. World Health Organization. Acute Respiratory Infections (Update September 2009): Streptococcus pneumoniae.

6. Musher Daniel M. Streptococcus pneumoniae. In: Mandell GL, Benett JE, Dolin R eds. Principles and Practice of Infectious Diseases $7^{\text {th }}$ ed. Elsevier, Philadelphia. 2010.

7. Sutliff WD, Findlan M. "Type 1 pneumococcal infections with especial reference to specific serum treatment". N. Engl. J. Med., 1934; 337: 970-976.

8. Sharma S, Maycher B, Eschun G. "Radiological imaging in pneumonia: recent innovations". Current Opinion in Pulmonary Medicine, 2007; 13(3): 159-69. https://doi. org/10.1097/MCP.0b013e3280f3bff4

9. Lim WS, Baudouin SV, George RC, Hill AT, Jamieson C, Le Jeune I, Macfarlane JT, Read RC, Roberts HJ, Levy ML, Wani M, Woodhead MA, Pneumonia Guidelines Committee of the BTS Standards of Care, Committee. "BTS guidelines for the management of community acquired pneumonia in adults: update 2009". Thorax., 64 (Suppl 3): iii1-55. https://doi.org/10.1136/ thx.2009.121434

10. Mandell LA, Wunderink RG, Anzueto A, Bartlett JG, Campbell GD, Dean NC, Dowell SF, File TM Jr, Musher DM, Niederman MS, Torres A, Whitney CG, Infectious Diseases Society of America; American Thoracic Society. "Infectious Diseases Society of America/ American Thoracic Society consensus guidelines on the management of community-acquired pneumonia in adults". Clinical infectious diseases: an official publication of the Infectious Diseases Society of America, 2007; 44(Suppl 2): S27-72. https://doi. org/10.1086/511159

11. Khan, S., Pritis, S., and Ankit, S. Bacteria etiological agents causing lower respiratory tract infections and their resistance patterns. Iranian Biomedical Journal, 2015; 19(4), 240.

12. Welt, T.,Torres, A. Clinical and economic burden of community- acquired pneumonia among adults in Europe. 2010. https://doi.org/10.1136/ thx.2009.129502

13. Whitney CG, Farley MM, Hadler J, Harrison LH, Lexau C, Reingold A, Lefkowitz L, Cieslak PR, Cetron M, Zell $E R$, Jorgensen $J H$, Schuchat $A$. Increasing prevalence of multidrug-resistant Streptococcus pneumoniae in the United States. Active Bacterial Core Surveillance Program of the Emerging Infections Program Network. N. Engl. J. Med. 2000; 28; 343(26): 1917-1924. https:// doi.org/10.1056/NEJM200012283432603

14. Yang $F, X u X G$, Yang MJ, Zhang YY, Klugman KP, McGee L. Antimicrobial susceptibility and molecular epidemiology of Streptococcus pneumoniae isolated from Shanghai, China. Int. J. Antimicrob Agents, 2008; 32(5): 386-391. https://doi.org/10.1016/j. ijantimicag.2008.05.004

15. Parija, S.C. Textbook of Microbiology \& Immuonology, 
$2^{\text {nd }}$ Edition, Elsevier. India . 2012.

16. Bush K. and Jacoby, G.A. Updated Functional classification of $\beta$-lactamases. Antimicrobial agents and chemotherapy, 2010; 54(3): 969-976. https://doi. org/10.1128/AAC.01009-09

17. Clinical and Laboratory Standards Institute CLSI. Performance standards for antimicrobial susceptibility testing; $26^{\text {th }}$ ed. Informational Supplement, 2016.

18. Ebihara, S., Ebihara, T. \& Kohzuki, M. Effect on aging on cough and swallowing Reflexes. Implication for preventing aspiration Pneumonia. Lung, 2012; 190(1): 29-33. https://doi.org/10.1007/s00408-011-9334-z

19. Barlett, J.G., Dwell, S.F., Mandell, L.A., File Jr, T.M., D.M \& Fine M.J. Practice guidelines for the management of community- acquired Pneumonia in adults. Clinical Infectious Diseases, 2000; 31(2): 347- 382. https://doi. org/10.1086/313954

20. Abdullahi, O., D'Amour, A., Xie, W., Weinberger, D.M., Tchetgen, E. Estimating rates of carriage acquisition and clearance and competitive ability for pneumococcal serotypes in Kenya with a Markov transition model. Epidemiology, 2012; 23(4): 510-519. https://doi.org/10.1097/EDE.0b013e31824f2f32

21. Olivier, le. Polain, de. Waroux, S. Flasche, A.J. Kucharski, C. Langendorf, D. Ndazima, J. MwangaAmumpaire, R. Grais, S. Cohuet, W. John, E.S. Identifying human encounters that shape the transmission of Streptococcus pneumonia and other acute respiratory infections. Epidemics, 2018; 25: 7279. https://doi.org/10.1016/j.epidem.2018.05.008

22. Yang, Z., Huang, Y.C.T., Koziel, H., De Crom, R., Ruetten,
H., Wohlfart, P. \& Colby, A. Female Resistance to pneumonia identifies lung Macrophage nitric oxide synthase -3as a therapeutic target. Elife, 2014; 3: 03711. https://doi.org/10.7554/eLife.03711

23. Amissah M.D. and Pappoe F. Prevalence of bacterial pathogens isolated from sputum cultures of hospitalized adult patients with community- acquired pneumonia at the cape coast teaching hospital, Ghana. E3 Journal of medical Research, 2014; 3(5): 56-61.

24. Motaweq, Z.Y. and Naher H.S. Antimicrobial susceptibility of Streptococcus pneumoniae isolates causing LRTI in Najaf, Iraq. Environmental \& Socioeconomic Studies, 2017; 5(2): 10-18. https://doi. org/10.1515/environ-2017-0007

25. Mahdi, A.S. Common Bacterial causes isolated from patients with community - acquired pneumonia . MSc. Thesis, Department of Microbiology, Collage of Medicine, University of Mustansiriya, Iraq. 2007.

26. Asadi A, Goudarzi M, Goudarzi H, Houri H, Ebrahimi $\mathrm{N}$, Bahri TD. Investigation and antibiotic susceptibility of Streptococcus pneumoniae isolated from patients with otitis. International Journal of Analytical, Pharmaceutical and Biomedical Sciences, 2015; 4(2): 2278-0246.

27. Wellington, E.M., Boxall, A.B., Cross, P., Feil, E.J., Gaze, W.H., Hawkey, P.M. \& Thomas, C.M. The Role of the natural environment in the emergence of antibiotic resistance in Gram-negative bacteria. The Lancet Infectious Diseases, 2013; 13(2): 155- 165. https:// doi.org/10.1016/S1473-3099(12)70317-1 